\begin{tabular}{|c|c|c|}
\hline $\begin{array}{l}\text { An International Biannual Open Access } \\
\text { Peer-Reviewed/Refereed Journal } \\
\text { JOURNAL OF GLOBAL RESOURCES } \\
\text { Published by : ISDESR, Jaipur, India }\end{array}$ & 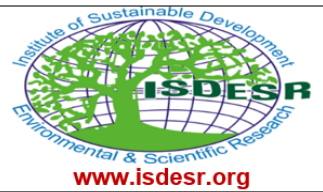 & $\begin{array}{r}\text { ISSN: } 2395-3160 \text { (Print) } \\
\text { ISSN: } 2455-2445 \text { (Online) } \\
\text { January 2022, Volume 08 (01) } \\
\text { DOI Prefix: } 10.46587 / \text { JGR }\end{array}$ \\
\hline
\end{tabular}

05

\title{
SYNTHESIS OF ACTIVATED CARBON AND CMC BEADS FROM CORN HUSK FOR EFFLUENT TREATMENT
}

\author{
Usha Sayed $^{1}$ and Swati Korgaonkar ${ }^{2}$ \\ ${ }^{1}$ Professor, ${ }^{2}$ Research Scholar \\ Department of Fibers and Textile Chemistry, \\ Institute of Chemical Technology, (ICT) Matunga, Mumbai, India \\ Email: swatikorgaonkar25@gmail.com
}

How to cite this paper:

Sayed, Usha and Korgaonkar, Swati (2022) Synthesis of activated carbon and $\mathrm{CMC}$ beads from Corn husk for effluent treatment, Journal of Global Resources, Vol. 08 (01)

DOI:

10.46587/JGR.2022.v08i01.005

Received: 13 Sep. 2021

Reviewed: 24 Oct. 2021

Revised: 05 Nov. 2021

Final Accepted: 14 Nov. 2021

Abstract: Adsorption of dyes from the effluent is a well-known and feasible method been used in the industry. In the present work we are using corn husk agricultural waste as a sustainable raw material for synthesizing activated carbon using biopolymer carboxyl methyl cellulose for formation of beads. The beads formed are been used for removal of reactive ultra-orange $R G B$, acid telon yellow FG 01, basic coracryl red C2B. The surface area of beads is $39.87 \mathrm{~m}^{2} / \mathrm{g}$. The maximum adsorption of reactive orange $R G B$, acid telon yellow and basic coracryl red is $68.25 \mathrm{mg} / \mathrm{g}, 72.54 \mathrm{mg} / \mathrm{g}$ and $30.21 \mathrm{mg} / \mathrm{g}$ for $50 \mathrm{ml}$ of dye solution. The stock solution $0.4 \mathrm{~g} / \mathrm{l}$ of dye solution was prepared for each dye respectively. The beads formed shows a variable $\mathrm{pH}$ from 2 to 12 which is favourable for textile effluent. This is a green approach to use the agricultural waste for waste water treatment.

Key word: Corn Husk, CMC Beads, Activated Carbon, Effluent Treatment, Adsorption. 


\section{Introduction}

The textile industry plants generally have a lot of effluent consisting of chemicals and dyes. The dyes used in textile industry consist of functional groups azo, nitro, anthraquinone, carbonyl and others. According to the figures it is evident that there is about 10000 different dyes and pigments which is been used industrially and about $7 \times 10^{5}$ tons of synthetic dyes are produced worldwide. Due to the inefficiency in textile dyeing in industries tons of dyes are been lost in the effluent during dyeing and finishing which leads to increasing BOD and COD to very high extent. (Singh $Z$. and Chadha $P, 2016$ ) The effluent is generally been dumped in the rivers and lakes directly without any treatment which causes a greater concern for the aquatic life. The dyes decrease the absorption and reflection of light entering the water which further alters the photosynthetic activity of algae (O. Loannidou, A. Zabaniotou, 2007). Dyes have some carcinogenic functional groups present in them which can cause severe damage to aquatic life if been exposed for a long duration of time. Industries are been imposed through strict laws due to environmental concerns. (Bisschops I. and Spanjers H, 2003) The effluent is undergone chemical or physical treatment to remove the hazardous chemicals from the effluent and then exposed it to the river. The dyes also consist of chlorine compound present in them which is carcinogenic to the aquatic organism as well as prolonged exposure can cause allergic reason as it is skin irritant.

Activated carbon available commercially are majorly been used due to its large surface area which makes its suitable for variable applications like agricultural usage, fuel storage, analytical chemistry, chemical purification, environmental chemistry etc. (El-Hendawy, 2008). The Biopolymer CMC is a natural polymer available in plants and other natural sources. It is water soluble polymer. The biopolymers are been used extensively due to its cheaper cost an ample of availability. The effluents treatment plant available in industry uses chemical and physical methods which are highly expensive. (Sharma S., Ruparelia J. and Patel M, 2011). In the present study we are focusing on a green approach to use the agricultural waste Corn husk. There is minimal use of chemicals to achieve a good adsorption of dyes which are been used in textile industry.

\section{Materials and Methods \\ Materials:}

The raw material used is Corn. Husk brought from Matunga market. The chemicals phosphoric acid (85 percent) pure, Calcium chloride anhydrous is obtained from LOBA chemicals. The dyes Ultra orange reactive dye and Acid telon yellow FG 01 is from Dystar India pvt. Itd. while the Basic coracryl red is obtained from colourtex industries Ltd.

\section{Methods:}

\section{a) Synthesis of activated carbon from C. Husk:}

$10 \mathrm{gms}$ of $\mathrm{C}$. husk is been weighed drenched in 75 percent of phosphoric acid overnight. The solution is heated at $85^{\circ} \mathrm{C}$ for 1 hour and then filtered through whatmann filter 41 . The filtrate id dried at $60^{\circ} \mathrm{C}$ till the filtrate dries completely. It is then put in the crucible and kept in muffle furnace at $450^{\circ} \mathrm{C}$ for 3 hours. The activated carbon obtained is then crushed in mortar and pestle into fine powder. (Arbia W., 2013)

\section{b) Synthesis of Activated carbon and CMC beads :}

The above obtained activated carbon is been characterised and then been used for the bead's formation. CMC is been used as a biopolymer.1 percent of CMC is been dissolved in distilled water. T. The dissolved $\mathrm{cmc}$ and activated carbon is been mixed and stirred for $1 \mathrm{hr}$. in highspeed stirrer. 2 percent $\mathrm{NaOH}$ is been used for the formation of beads. The activated carbon mixture is been added in $\mathrm{NaOH}$ solution slowly and been kept for stirring overnight. (Keharia $\mathrm{H}$. and Madamwar D, 2003) The beads formed are been crosslinked with 2 percent of calcium 
chloride to increasing the rate of adsorption of the dye solution. The beads formed are dried and crushed and been further used for experimentation.

\section{c) Application of formed beads:}

The beads which are formed without crosslinking and with crosslinking are been studies for its adsorption capacity. The Stock dye solution of $0.4 \mathrm{~g} / \mathrm{L}$ is been prepared for Reactive ultra-orange, acid telon yellow and basic coracryl red dye. The optimization of the prepared solution at various adsorption dosage, $\mathrm{pH}$ and time is been studied.

\section{Results and Discussions}

The prepared activated carbon and beads are been characterised for surface area analysis and methylene blue test for confirming the presence of activated carbon.

a) BET surface area analysis: BET surface area analysis was done using Micromeritics ASAP2020, USA instrument. The activated carbon (AC) samples were measured at liquid nitrogen temperature $(77 \mathrm{~K})$

Table 01: BET Analysis

\begin{tabular}{|l|c|c|}
\hline Properties & CAC & CACC \\
\hline Total Surface area, $\mathrm{m} 2 / \mathrm{g}$ & 21.86 & 26.42 \\
\hline Total Pore Volume, $\mathrm{cm} 3 / \mathrm{g}$ & 0.0254 & 0.0271 \\
\hline Average Pore Diameter, $\AA$ & 43.12 & 39.87 \\
\hline
\end{tabular}

The surface area through BET analysis shows that the surface area before crosslinking $(C A C)$ is $21.86 \mathrm{~m}^{2} / \mathrm{g}$ while it is increasing after crosslinking (CACC) i.e., $26.42 \mathrm{~m} 2 / \mathrm{g}$. As the surface area increases the adsorption capacity also increases.

b) Methylene blue test: Methylene Blue (MB) value indicates the maximum volume of standard MB solution ( 0.15 percent) decolorized by a fixed amount of AC. Standard MB solution (0.15 percent) was made and allowed to stand overnight (11). Carefully weighed $0.1 \mathrm{~g} \mathrm{AC}$ was added to a flask containing $5 \mathrm{~mL}$ of MB solution. It was then shaken to decolorize and instead of conventional method of taking readings after $5 \mathrm{~min}$, readings were taken after $5 \mathrm{~min}$, $6 \mathrm{~h}$ and 24 $h$ to achieve best results. The entire volume of $M B$ was recorded and then $M B$ value is reported in $\mathrm{mg} / \mathrm{g}$. (Safa Y. and Bhatti $\mathrm{H}, 2010$ ), (11)

Table 02: Methylene Blue Adsorption Test

\begin{tabular}{|c|c|c|c|}
\hline Carbon loading in g/CAC & 5min & 6hrs & 24hrs \\
\hline 0 & 64.82 & 138.52 & 214.08 \\
\hline 2.5 & 208.12 & 476.27 & 951.25 \\
\hline 5 & 219.64 & 657.38 & 1151.19 \\
\hline 7.5 & 237.49 & 842.46 & 1254.26 \\
\hline 10 & 249.31 & 904.39 & 1329.31 \\
\hline
\end{tabular}

It is been observed that there is an increase in adsorption with increase in carbon loading. With increase in activated carbon for the prepared solution there is an increase in adsorption value. It is also been observed that there is no distinct in adsorption capacity at $10 \mathrm{gm}$ of carbon loading. This behaviour is due to presence of carbon and its porous nature. (McKay G., Choy H, 2000) Further with increase in time the adsorption increases. The readings were taken at $5 \mathrm{~min}, 6$ hours and 24 hours interval which shows an evident increase in adsorption capacity for CAC beads i.e., at $2.5 \mathrm{~g}$ of carbon loading it shows an adsorption of $208.12 \mathrm{mg} / \mathrm{l} 476.27 \mathrm{mg} / \mathrm{l}$ and $951.25 \mathrm{mg} / \mathrm{l}$ respectively. c) Characterization of beads through FTIR. The analysis of the surface functional groups present on the ACs was done using SHIMADZU 8400 S FTIR spectrophotometer, Japan. Samples were ground to make a powder and readings were taken in powder form. The organic compounds present $3334.51 \mathrm{~cm}^{-}$ ${ }^{1} \mathrm{NH}$ stretching, $2919 \mathrm{~cm}^{-1} \mathrm{NH}$ stretch amine salt, $1726 \mathrm{~cm}^{-1} \mathrm{CH}$ bending, $1634 \mathrm{~cm}^{-1} \mathrm{C}=\mathrm{C}$ stretch alkene, $1371 \mathrm{~cm}^{-1} \mathrm{NO}$ stretch, $1243.72 \mathrm{~cm}^{-1} \mathrm{CF}$ stretch, $1155.2 \mathrm{~cm}^{-1}$ SO stretching, $1035.03 \mathrm{~cm}^{-1} \mathrm{Co}$ stretching. The fig 2 is given in the fig uploads. 
Figure 01: FTIR

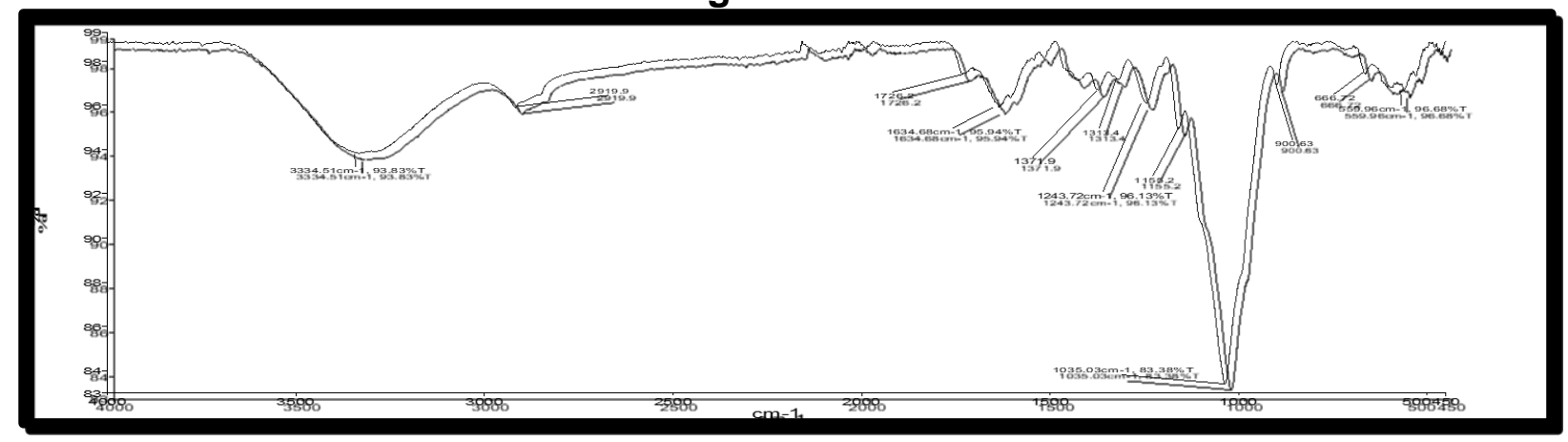

c) Batch adsorption studies: Adsorption studies were carried out for reactive ultra-orange, acid telon yellow FG 01, basic coracyl red. The adsorption of the two-adsorbate activated carbon and $\mathrm{CMC}(\mathrm{CAC})$ and with cross linking with $\mathrm{CaCl}_{2}$ (CACC) were optimised for various parameters.

\section{1) Effect of contact time for Reactive ultra-orange RGB:}

From table 3 it is been observed that the rate of adsorption initially is higher and as time progresses; it decreases for both the adsorbents. At the initial stage, higher numbers of adsorption sites are available. With increase in time, saturation of adsorption sites takes place thereby reducing the efficiency of adsorption. For CAC it is seen that after 8 hours there is hardly any increase in adsorption and hence increase in adsorption capacity while that of CACC there is a huge increase in adsorption capacity as compared to CAC with time. The reason behind such a distinct difference between adsorption capacities of CAC and CACC beads can be the higher porosity of AC in CACC beads.

Table 03: Effect of contact Time of CAC and CACC on Reactive dye

\begin{tabular}{|c|c|c|}
\hline Time & CAC & CACC \\
\hline 1 & 1.54 & 24.87 \\
\hline 2 & 7.31 & 32.74 \\
\hline 4 & 11.38 & 43.38 \\
\hline 6 & 13.43 & 68.91 \\
\hline 8 & 18.72 & 128.18 \\
\hline 16 & 19.19 & 139.09 \\
\hline 24 & 19.23 & 146.35 \\
\hline 32 & 18.89 & 150.87 \\
\hline
\end{tabular}

\section{2: Effect of pH:}

To study the effect of pH of dye solution on adsorption capacities of CAC and CACC beads, $50 \mathrm{ml}$ of $400 \mathrm{mg} / \mathrm{L}$ dye solution was treated with $0.1 \mathrm{~g}$ of adsorbent beads at $\mathrm{pH}$ of 2 to 12 at the intervals of 2 by adjusting the $\mathrm{pH}$ using $0.1 \mathrm{~N}$ of $\mathrm{HCl}$ and $0.1 \mathrm{~N} \mathrm{NaOH}$. Readings were taken after 12 h. From table 4 it is been observed that with increase in $\mathrm{pH}$ there is a decrease in adsorption capacity. There is a significant higher adsorption at $\mathrm{pH}$ 2. The AC loading in CACC decreases due to the available number of amine groups, which are solely due to the lower amount of CMC present in CACC. Thus, the electrostatic attraction in this case is not the predominant mechanism and adsorption may be only due to weak physical forces like Van der Waal's, hydrogen bonding, dipole-dipole. (Safa Y. and Bhatti $H, 2010)$, (11)

Table 4: Effect of pH on Adsorption Capacity of Reactive Dye

\begin{tabular}{|c|c|c|}
\hline \multirow{2}{*}{$\mathbf{p H}$} & \multicolumn{2}{|c|}{ Adsorption Capacity } \\
\cline { 2 - 3 } & CAC & CACC \\
\hline 2 & 368.56 & 246.31 \\
\hline 4 & 72.91 & 185.46 \\
\hline 6 & 46.31 & 141.29 \\
\hline 8 & 28.09 & 108.23 \\
\hline 10 & 15.27 & 108.23 \\
\hline 12 & 10.46 & 108.31 \\
\hline
\end{tabular}




\section{3: Effect of adsorbent dosage:}

While checking the effect of adsorbent dosage on adsorption capacity of CAC and CACC beads, $50 \mathrm{ml}$ dye solution of $400 \mathrm{mg} / \mathrm{L}$ dye concentration was treated with different adsorbent beads quantities, $0.05,0.10 .15$ and $0.2 \mathrm{~g}$ at $\mathrm{pH} 6$ and samples were taken after $16 \mathrm{~h}$.

Table 05: Effect of adsorbate dosage on adsorption capacity of Reactive dye

\begin{tabular}{|c|c|c|}
\hline \multicolumn{3}{|c|}{ Initial Concentration 400mg/l, Contact Time 16hrs, $\mathrm{pH}: 6$} \\
\hline & \multicolumn{2}{|c|}{ Adsorption Capacity in $\mathrm{mg} / \mathrm{L}$} \\
\hline Adsorbent Dosage $(\mathrm{g} / 50 \mathrm{ml})$ of dye solution & CAC & CACC \\
\hline 0.05 & 15.34 & 68.42 \\
\hline 0.1 & 13.57 & 64.89 \\
\hline 0.15 & 10.87 & 63.67 \\
\hline 0.2 & 10.98 & 60.25 \\
\hline
\end{tabular}

From table 5 it was observed that with increase in the absorbent dosage there is a decrease in adsorption capacity. However, with increasing adsorbent dose, the quantity of dye adsorbed on to the unit weight of the adsorbent gets reduced. This may be attributed to overlapping or aggregation of adsorption sites, leading to a decrease in total adsorbent surface area available to the dye and an increase in diffusion path length. (13)

\section{4: Effect of AC loading:}

While investigating effect of $A C$ loading, $50 \mathrm{ml}$ of dye solution of $400 \mathrm{mg} / \mathrm{L}$ concentration was treated with $0.1 \mathrm{~g}$ of adsorbent at $\mathrm{pH} 6$ and the samples were taken after $16 \mathrm{~h}$. In this case, CAC beads were considered as beads with composition $0 \mathrm{~g}$ of $\mathrm{AC} / 1 \mathrm{~g}$ of $\mathrm{CMC}$ and the $\mathrm{AC}$ dosage was increased as 2.5, 5.0, 7.5 and $10 \mathrm{~g}$ of $\mathrm{AC} / 1 \mathrm{~g}$ of CMC.

Table 06 : Effect of Adsorbent dosage on adsorption capacity of Reactive dye

\begin{tabular}{|c|c|}
\hline \multicolumn{2}{|c|}{ Initial Concentration 400mg/l, Contact Time 16hrs, $\mathrm{pH}: 6$} \\
\hline AC Loading g / g of CMC & Adsorption Capacity, mg/g \\
\hline 0 & 3.84 \\
\hline 2.5 & 18.65 \\
\hline 5 & 40.87 \\
\hline 7.5 & 60.42 \\
\hline 10 & 69.65 \\
\hline
\end{tabular}

It can be observed from the table 6, that as the concentration of $A C$ in $C M C$ beads is increased, the adsorption capacity increased linearly. As concentration of $A C$ is increased in $C M C$ beads, more and more AC gets embedded inside the beads and also on the surface of beads. As $A C$ is having higher surface area, higher numbers of adsorption sites are available and hence adsorption capacity increases with increase in AC loading.

\section{5: Adsorption Isotherm:}

To investigate the type of adsorption isotherm for CAC and CACC beads, dye solution of variable initial concentrations such as $200,400,600,800$ and $1000 \mathrm{mg} / \mathrm{L}$ were treated with adsorbent at $\mathrm{pH} 6$ and the samples were taken after $16 \mathrm{~h}$. The study was subjected to three different models i.e., Langmuir isotherm, Freundlich isotherm and Temkin isotherm. On the basis of $R^{2}$ values, it can be concluded that applicability of the model in case of CAC was in the following order, Langmuir > Temkin > Freundlich. Hence Langmuir was found to be the best suited model for CAC beads (11). The equilibrium factor value $\left(R_{I}\right)$ is found to be 0.55 showing favourability to Langmuir model. monolayer adsorption capacity of the CAC beads (Q0) of $52.04 \mathrm{mg} / \mathrm{g}$. Bonding energy was found to be $0.0043 \mathrm{~L} / \mathrm{mg}$. There is a high correlation coefficient of 0.99 according to the Langmuir adsorption, which indicates that there is strong interaction between the dye molecules and $\mathrm{CMC}$. 
Table 07: Adsorption Isotherm for adsorption of Reactive dye

\begin{tabular}{|l|l|c|c|}
\hline Isotherm & Parameters & CAC & CACC \\
\hline Langmuir & $\mathrm{Q}, \mathrm{mg} / \mathrm{g}$ & 52.04 & 287.58 \\
\cline { 2 - 4 } & $\mathrm{B}, \mathrm{L} / \mathrm{mg}$ & 0.0043 & 0.0018 \\
\cline { 2 - 4 } & $\mathrm{R} 2$ & 0.99 & 0.997 \\
\cline { 2 - 4 } & $\mathrm{RL}$ & 0.55 & 0.7924 \\
\hline \multirow{5}{*}{ Freundlich } & $\mathrm{n}$ & 2.27 & 1.418 \\
\cline { 2 - 4 } & $\mathrm{Kf},(\mathrm{mg} / \mathrm{g})(\mathrm{L} / \mathrm{mg}) 1 / \mathrm{n}$ & 2.08 & 1.408 \\
\cline { 2 - 4 } & $\mathrm{R} 2$ & 0.94 & 0.996 \\
\hline \multirow{5}{*}{ Temkin } & $\mathrm{Bt}, \mathrm{J} / \mathrm{mol} / \mathrm{k}$ & 214.04 & 46.7 \\
\cline { 2 - 4 } & $\mathrm{At}, \mathrm{L} / \mathrm{g}$ & 0.03 & 0.02 \\
\cline { 2 - 4 } & $\mathrm{R} 2$ & 0.98 & 0.965 \\
\hline
\end{tabular}

On the other hand, in case of CACC beads, applicability of adsorption isotherms on the basis of $R^{2}$ values was observed in the following order, Langmuir > Freundlich > Temkin. Both Langmuir and Freundlich isotherm models were found to have similar values of R2 as 0.997 and 0.996, respectively, which are near to unity. However, the calculated qeq values from Langmuir model agreed well with the experimental values, covering most of the data points as in shown in table 7. It can, therefore, be concluded that both Langmuir and Freundlich isotherm models show applicability in case of CACC. In case of CACC beads, monolayer adsorption capacity (Q0) was found to be very high compared to CAC beads, possibly due to highly porous nature of AC. Positive values of heat of adsorption (Bt) obtained from Temkin isotherm, $214.04 \mathrm{~J} / \mathrm{mol} / \mathrm{k}$ and 46.7 $\mathrm{J} / \mathrm{mol} / \mathrm{k}$, for CAC and CACC beads, respectively, show that adsorption of dye is endothermic.

\section{6: Adsorption Kinetics:}

To investigate the adsorption kinetics, the beads were treated with dye solution of $400 \mathrm{mg} / \mathrm{L}$ at pH 6. Samples were taken at interval of 20,40, 60, 80, 100, 120, 240, 360, 480, 600, 720, 840, 960, 1080, 1200, 1320, 1440, 1560, 1680, 1800, 1930, 2040 and 2160 min. Three adsorption kinetics were studied, namely, pseudo first order kinetics, pseudo second order kinetics and intraparticle diffusion kinetics.

Table 08: Adsorption Kinetics for Adsorption of Reactive dye

\begin{tabular}{|c|c|c|c|}
\hline Kinetic Model & Parameter & CAC & CACC \\
\hline \multirow{3}{*}{ First-order } & $\mathrm{K} 1, \mathrm{mg} / \mathrm{g} / \mathrm{min}$ & $1.28 \times 10^{\wedge}-03$ & $1.87 \times 10^{\wedge}-03$ \\
\hline & qeq, $\mathrm{mg} / \mathrm{g}$ & 11.86 & 158.25 \\
\hline & R 2 & 0.87 & 0.95 \\
\hline \multirow{3}{*}{ Second-order } & $\mathrm{K} 2, \mathrm{mg} / \mathrm{g} / \mathrm{min}$ & $1.52 \times 10^{\wedge}-04$ & $1.537 \times 10^{\wedge}-05$ \\
\hline & qeq, $\mathrm{mg} / \mathrm{g}$ & 16.89 & 178.84 \\
\hline & $\mathrm{R} 2$ & 0.98 & 0.99 \\
\hline \multirow{4}{*}{ Intra-particle } & $\mathrm{Kid}, \mathrm{mg} / \mathrm{g} / \mathrm{Vt}$ & 1.18 & 10.45 \\
\hline & $\mathrm{I}, \mu \mathrm{g} / \mathrm{g}$ & 0.29 & 3.47 \\
\hline & qeq, $\mathrm{mg} / \mathrm{g}$ & 56.38 & 175.81 \\
\hline & $\mathrm{R} 2$ & 0.92 & 0.94 \\
\hline Experimental & qeq, $\mathrm{mg} / \mathrm{g}$ & 14.87 & 160.47 \\
\hline
\end{tabular}

It can be clearly seen in table 8 , that CAC beads adsorption follows pseudo second order model from the beginning of adsorption process. Pseudo first order kinetics was observed as better fit for CAC adsorption after the maximum adsorption was achieved. Maximum adsorption (almost 50 percent) was achieved within initial $4 \mathrm{~h}$ and the equilibrium attained within 8 to $10 \mathrm{~h}$. Higher correlation value $\left(R^{2}\right)$ of 0.98 for second order kinetics indicates chemisorption mechanism. It can be observed that up to $4 \mathrm{~h}$, CACC beads follow second order kinetics; from 4 to $8 \mathrm{~h}$ first order kinetics is followed and thereafter again second order. However, for overall duration of adsorption, pseudo second order model proved to be best fit with maximum correlation value of 0.99 . (12) The reason behind such dramatic shift of model can be attributed to the 
presence of porous $A C$ and its higher rate of adsorption. Also, pseudo second order adsorption constant for CACC beads was found to be almost 10 times higher than that of CAC beads, which can be explained only by physio sorption of AC. Similarly, the adsorption was been examined for the other three dyes.

\section{Acid Tellon yellow FG01}

From table 9 it is been observed that the rate of adsorption initially is higher and as time progresses; it decreases for both the adsorbents. In case of CAC beads, adsorption capacity of acid tellon yellow FG 01 was continued even after $8 \mathrm{~h}$, unlike RR2 where equilibrium was observed within $8 \mathrm{~h}$. Also, adsorption capacity for acid dye $(42.19 \mathrm{mg} / \mathrm{g})$ was observed to be higher as compared to Reactive dye $(18.89 \mathrm{mg} / \mathrm{g})$, which may be as a result of lower molecular weight of acid dye which helped in better penetration of dye molecule. In case of CACC beads, rate of adsorption was observed to be very much more for initial 2 to $6 \mathrm{~h}$, which gradually increases until equilibrium is achieved after $16 \mathrm{~h}$.

Table 09: Effect of contact Time of AC and CAC on Acid dye

\begin{tabular}{|c|c|c|}
\hline Time & CAC & CACC \\
\hline 1 & 7.25 & 20.87 \\
\hline 2 & 9.87 & 28.97 \\
\hline 4 & 13.54 & 34.52 \\
\hline 6 & 18.62 & 55.63 \\
\hline 8 & 28.35 & 102.81 \\
\hline 16 & 38.65 & 105.61 \\
\hline 24 & 42.54 & 108.61 \\
\hline 32 & 42.19 & 112.89 \\
\hline
\end{tabular}

The mere observation from table 10 was been made that both adsorbents have higher adsorption in acidic $\mathrm{pH}$ instead of alkaline. For $\mathrm{CAC}$ beads, adsorption was highest in $\mathrm{pH}$ range of 2 to 4 , which then decreased up to $\mathrm{pH} 10$ with no change thereafter till $\mathrm{pH} 12$.

Table 10: Effect of pH on adsorption capacity of Acid dye

\begin{tabular}{|c|c|c|}
\hline \multirow{2}{*}{$\mathbf{p H}$} & \multicolumn{2}{|c|}{ Adsorption Capacity } \\
\cline { 2 - 3 } & CAC & CACC \\
\hline 2 & 42.12 & 104.23 \\
\hline 4 & 46.37 & 100.89 \\
\hline 6 & 35.09 & 100.02 \\
\hline 8 & 16.52 & 92.8 \\
\hline 10 & 12.61 & 87.56 \\
\hline 12 & 10.82 & 75.62 \\
\hline
\end{tabular}

The reason behind higher adsorption in acidic $\mathrm{pH}$ can be protonation of amine groups of CMC molecule which will attract negative dye anions, similar to the anionic dye (Reactive dye). In case of CACC beads are concerned, adsorption was highest ( 104.23 to $92.8 \mathrm{mg} / \mathrm{g}$ ) in the range of $\mathrm{pH} 2$ to 8 , from where it decreases rapidly to $75.62 \mathrm{mg} / \mathrm{g}$ at $\mathrm{pH} 12$. The increased range of $\mathrm{pH}$ (4 to 8 ) of maximum adsorption, observed in case of CACC beads, can be due to physical adsorption by AC.

Table 11: Effect of adsorbate dosage on adsorption capacity of Acid dye

\begin{tabular}{|c|c|c|}
\hline \multicolumn{3}{|c|}{ Initial Concentration 400mg/l, Contact Time 16hrs, $\mathrm{pH}: 6$} \\
\hline Adsorbent Dosage $(\mathrm{g} / 50 \mathrm{ml})$ of dye solution & Adsorption Capacity in mg/L \\
\hline & CAC & CACC \\
\hline 0.05 & 50.32 & 62.54 \\
\hline 0.1 & 28.25 & 67.16 \\
\hline 0.15 & 24.3 & 56.35 \\
\hline 0.2 & 19.45 & 52.46 \\
\hline
\end{tabular}


From table 11, it is been observed that CAC beads adsorption capacity decreased from $50.32 \mathrm{mg} / \mathrm{g}$ to $19.45 \mathrm{mg} / \mathrm{g}$ as adsorbent dosage is increased from 0.05 to $0.2 \mathrm{~g} / 50 \mathrm{ml}$ dye solution, whereas in case of CACC beads, adsorption capacity decreased from $72.54 \mathrm{mg} / \mathrm{g}$ to $52.46 \mathrm{mg} / \mathrm{g}$. It can be justified as increase in adsorption dosage is causing decrease the adsorption density. This is due to the lower amount of the dye available per unit mass of adsorbent.

From table 12, observation is been made that adsorption capacity increased linearly from $27.45 \mathrm{mg} / \mathrm{g}$ to $79.82 \mathrm{mg} / \mathrm{g}$, with increase in concentration of $A C$ in beads. The rate of increase in dye adsorption in case of acid dye is lower compared to that of reactive dye. This may be due to molecular weight difference. As in case of reactive dye, molecular weight is higher compared to acid dye , hence reactive dye was observed to have higher affinity for $A C$ and hence higher rate of adsorption.

Table 12: Effect of Adsorbent Dosage on Adsorption Capacity of Acid Dye

\begin{tabular}{|c|c|}
\hline \multicolumn{2}{|c|}{ Initial Concentration 400mg/l, Contact Time 16hrs, $\mathrm{pH}: 6$} \\
\hline AC Loading g/g of CMC & Adsorption Capacity, mg/g \\
\hline 0 & 27.45 \\
\hline 2.5 & 42.61 \\
\hline 5 & 57.21 \\
\hline 7.5 & 64.38 \\
\hline 10 & 79.82 \\
\hline
\end{tabular}

Table 13: Adsorption Isotherm for Adsorption of Acid Dye

\begin{tabular}{|c|l|c|c|}
\hline Isotherm & Parameters & CAC & CACC \\
\hline \multirow{5}{*}{ Langmuir } & $\mathrm{Q} 0, \mathrm{mg} / \mathrm{g}$ & 29.87 & 155.61 \\
\cline { 2 - 4 } & $\mathrm{B}, \mathrm{L} / \mathrm{mg}$ & 0.0108 & 0.0026 \\
\cline { 2 - 4 } & $\mathrm{R} 2$ & 0.96 & 0.95 \\
\cline { 2 - 4 } & $\mathrm{RL}$ & 0.3084 & 0.6234 \\
\hline \multirow{3}{*}{ Freundlich } & $\mathrm{n}$ & 4.35 & 2.08 \\
\cline { 2 - 4 } & $\mathrm{Kf},(\mathrm{mg} / \mathrm{g})(\mathrm{L} / \mathrm{mg}) 1 / \mathrm{n}$ & 6.48 & 4.18 \\
\cline { 2 - 4 } & $\mathrm{R} 2$ & 0.91 & 0.97 \\
\hline \multirow{3}{*}{ Temkin } & $\mathrm{Bt}, \mathrm{J} / \mathrm{mol} / \mathrm{k}$ & 517.08 & 73.47 \\
\cline { 2 - 4 } & $\mathrm{At}, \mathrm{L} / \mathrm{g}$ & 0.27 & 0.02 \\
\cline { 2 - 4 } & $\mathrm{R} 2$ & 0.94 & 0.93 \\
\hline
\end{tabular}

On the basis of $R^{2}$ values, it can be concluded that applicability of the model in case of CAC was in following order, Langmuir > Temkin > Freundlich. Hence Langmuir was found to be the best suited model for CAC beads. It indicates homogeneous structure of adsorbent. Also, sorption is taken place at definite sites, indicating presence of chemisorption. The CACC beads were observed to follow Freundlich isotherm model with correlation coefficient of 0.97 , rather than Langmuir model (0.95) and Temkin model (0.93). Applicability of Freundlich model denotes presence of heterogeneous surface because of both AC and CMC. Also, it can also be stated that CACC beads are following multilayer adsorption, which can be main reason behind such higher adsorption abilities of CACC.

It can be denoted from correlation coefficient value of 0.94 that $\mathrm{CAC}$ beads are following pseud second order kinetics instead of pseudo first order kinetics $(0.86)$ and intra particle diffusion (0.93). It is been observed that for initial $8 \mathrm{hr}$ CAC beads are following intraparticle diffusion and once equilibrium is reached its following first order kinetics. In case of CACC beads, it can be observed that adsorbent is following intra particle diffusion for $16 \mathrm{~h}$ and once equilibrium is achieved it is following second order adsorption. 
Table 14 : Adsorption Kinetics for Adsorption of Acid dye

\begin{tabular}{|c|c|c|c|}
\hline Kinetic Model & Parameter & CAC & CACC \\
\hline \multirow{3}{*}{ First-order } & $\mathrm{K} 1, \mathrm{mg} / \mathrm{g} / \mathrm{min}$ & $-2.56 \times 10^{\wedge}-03$ & $-1.42 \times 10^{\wedge}-03$ \\
\cline { 2 - 4 } & $\mathrm{qeq}, \mathrm{mg} / \mathrm{g}$ & 42.87 & 107.15 \\
\cline { 2 - 4 } & $\mathrm{R} 2$ & 0.86 & 0.87 \\
\hline \multirow{3}{*}{ Second-order } & $\mathrm{K} 2, \mathrm{mg} / \mathrm{g} / \mathrm{min}$ & $3.29 \times 10-05$ & 130.58 \\
\cline { 2 - 4 } & $\mathrm{qeq}, \mathrm{mg} / \mathrm{g}$ & 54.68 & 0.97 \\
\cline { 2 - 4 } & $\mathrm{R} 2$ & 0.94 & -6.29 \\
\hline \multirow{3}{*}{ Intra-particle } & $\mathrm{Kid}, \mathrm{mg} / \mathrm{g} / \mathrm{/t}$ & -0.74 & 2.35 \\
\cline { 2 - 4 } & $\mathrm{I}, \mu \mathrm{g} / \mathrm{g}$ & 50.19 & 104.21 \\
\cline { 2 - 4 } & $\mathrm{qeq}, \mathrm{mg} / \mathrm{g}$ & 0.93 & 102.98 \\
\hline
\end{tabular}

\section{Conclusions}

The synthesis of activated carbon beads using corn husk agricultural waste and CMC biopolymer for studying the adsorption characteristic of reactive ultra-orange dye, acid tellon yellow FG01, basic coracryl red and direct red dye is been carried out successfully. The CMC beads were crosslinked with calcium chloride forming ionic bond, studies showed an increase in adsorption capacity as compared to the non-crosslinked $\mathrm{CMC}$ beads. The variable $\mathrm{pH}$ range of crosslinked beads i.e., from 2 to 12 makes its suitable for actual textile effluent which is generally alkaline in nature. The CAC beads are following Langmuir adsorption isotherm irrelevant of the adsorbate. While the CACC beads are following Freundlich for acid and basic dye on the basis of coefficient of correlation values while reactive and direct dye are following both Freundlich and Langmuir isotherm due to presence of activated carbon. The kinetics were also been studied for both CAC and CACC beads showing second order kinetics for both the adsorbent indicating chemisorption.

\section{Reference}

1. Singh Z. and Chadha P. (2016). Textile industry and occupational cancer. Journal of Occupational Medicine and Toxicology. 11-39.

2. Bisschops I. and Spanjers H. (2003). Literature review on textile wastewater characterization. Environmental Technology. 24: 1399-1411.

3. El-Hendawy, A.A., Alexander, A.J., Andrews, R.J. Forrest G. (2008). Effects of activation schemes on porous, surface and thermal properties of activated carbons prepared from cotton stalks. Journal of Analytical and Applied Pyrolysis. Vol. 82: 272-278.

4. O. Ioannidou, A. Zabaniotou. (2007). Agricultural residues as precursors for activated carbon production - A review. Renewable and Sustainable Energy Reviews 11:pp 1976.

5. Sharma S., Ruparelia J. and Patel M. (2011). A general review on Advanced Oxidation Processes for wastewater treatment. International Conference on Current Trends in Technology. 382-481.

6. Keharia H. and Madamwar D. (2003). Bioremediation concepts for treatment of dye containing wastewater: a review. Indian Journal of Experimental Biology.41: 1068- 1075.

7. Safa Y. and Bhatti H. (2010). Factors affecting biosorption of direct dyes from aqueous solution. Asian Journal of Chemistry. 22 (9): 6625-6639.

8. Arbia W., Arbia L., Adour L. and Amrane A. (2013). Chitin extraction from crustacean shells using biological methods - a review. Food Technology Biotechnology.51 (1): 12-25.

9. McKay G., Choy H. and Porter F. (2000). Langmuir isotherm models applied to the multicomponent sorption of acid dyes from effluent onto activated carbon. Journal of Chemical and Engineering Data. 45: $575-584$.

10. Malik P. (2004). Dye removal from wastewater using activated carbon developed from sawdust: adsorption equilibrium and kinetics. Journal of Hazardous Materials. B.113: 81-88.

11. P.V. Thitame, S.R. Shukla (2016). Adsorptive removal of reactive dyes from aqueous solution using activated carbon synthesized from waste biomass material.

12. Swatantra P. Singh, Karthik Rathinam, Tarun Gupta, Avinash Kumar Agarwal (2021). Nanomaterials and Nanocomposites for Environmental Remediation.

13. Haluk Aydin (2006). Adsorption of acid dyes in aqueous solutions by shells of bittim (Pistacia khinjuk Stocks) 